\title{
Adsorption of Heavy Metal Ions from Aqueous Media Using Amidoximated Jute Fibres: A Comparative Study
}

\author{
M. S. Hassan, N. M. Ali, R. M. Attia, M. H. Zohdy and
}

\section{A. M. Rabie*}

Radiation Chemistry Dept., National Centre for Radiation Research and Technology (NCRRT), B. O. Box; 29 Nasr City, Egypt. "Chemistry Dept., Faculty of Sciences, Ain Shams Univ., Egypt.

\footnotetext{
JUTE FIBERS were grafted with acrylonitrile (AN) induced by direct gamma irradiation. All the factors which affect the grafting process were investigated. The grafting at the optimum conditions was followed by amidoximation reaction. The conversion of AN into acrylamidoxime was studied by fourier transform infrared (FT-IR) spectroscopy, X-ray diffraction (XRD), scanning electron microscopy (SEM) and thermogravimetric analysis (TGA). The treated Jute fibres were used as an adsorbent substrate for heavy metal ions such as $\mathrm{Pb}^{2+}$, $\mathrm{Cu}^{2+}, \mathrm{Ni}^{2+}$ and $\mathrm{Fe}^{2+}$ from their solutions. The different factors which affect the adsorption capacity of heavy metal ions, such as $\mathrm{pH}$, contact time, metal ions concentrations were studied and the Langmuir adsorption isotherm was highlighted. It was found that the adsorption capacity was enhanced at acidic medium of $\mathrm{pH} 4$ and increased with increasing of contact time.

Keywords: Amidoxime, metal removal, jute fibres, $\gamma$-rays, adsorption isotherm.
}

Heavy metal pollution can cause serious environmental problems due to its toxic and carcinogenic effects on the natural environment and its accumulation in living organisms (Liu, et al., 2008). The toxicity of heavy metals might be caused by blocking essential functional groups of biomolecules and by disrupting the integrity of bio-membranes (Bayramoglu et al., 2007). In recent years, the removal of hazardous heavy metals from water and soil environments and industrial waste steams has attracted considerable attention. Enhanced metal separation techniques that require less energy with minimal impact on the environment are desirable. In order to remove dissolved heavy metal ions from various environments, conventional techniques including chemical precipitation, 

ion exchange, reverse osmosis, membrane separation, electrochemical treatments and solvent extraction processes are widely used (Akkaya et al., 2008 and Jang et al., 2008). In general, these techniques are often costly or ineffective, especially in removing heavy metal ions at low concentrations (Laus et al., 2011). Radiation-induced grafting polymerization is widely used to produce high performance chemically active polymer materials for adsorption and separation processes on the basis of various commercial polymers available in different forms (films, fibres, resins, textiles, powders) (Bhattacharya et al., 2004). Directly grafting desirable functional groups to polymer is one of approaches to synthesize polymer adsorbents. Adsorbents can be easily synthesized by radiation-induced graft polymerization. In this regards, the radiation was induced the grafting process with poly-AN, in which the nitrile groups can be converted into amidoxime groups (Nasef et al., 2004). Chelating polymer adsorbents containing amidoxime groups have been considerable attention in the separation of heavy metals due to its ability to form chelates (Badawy et al., 2006).

Jute is one of the most affordable natural fibres and it is the second to cotton in amount produced and variety of its raw material extracted from vegetable fibres. It is also cheap, contains huge interspaces and can be used easily as a wastewater effluent filtration. Jute fibres are composed primarily of the plant materials cellulose and lignin. In the present work, Jute fibres were grafted with AN by gamma radiation technique, then the nitrile groups were converted into amidoxime groups, to use as an adsorbent substrate for some heavy metal ions such as: $\mathrm{Fe}^{+2}, \mathrm{~Pb}^{2+}, \mathrm{Cu}^{2+}$ and $\mathrm{Ni}^{2+}$. The characterization of amidoximated grafted Jute fibres and the effect of different parameters on its adsorption capacity for metal ions were investigated.

\section{Experimental}

\section{Materials}

AN-monomer MW of 53.06 was supplied by Ranbaxy, India. Jute fibres were supplied by the Egyptian Company for Jute Production, Egypt. The Jute fibers were soaked into $20 \% \mathrm{NaOH}$ solution for $24 \mathrm{~h}$., followed by washing with distilled water until pH7 was achieved. Ammonium hydroxide, Ammonium chloride, Sodium hydroxide, Nickel sulphate, Ethylene diamine tetra acetic acid (EDTA), Cupric sulphate and Glacial acetic acid were supplied by El-Nasr Pharmaceutical Egypt. J. Rad. Sci. Applic., Vol. 28, No. 1-2 (2015) 
Chemicals Co., Egypt. Lead nitrate was supplied by Alpha Chemika Co., India. Ammonium ferrous sulphate was supplied by BDH chemicals Ltd., England. All chemical reagents used were all of analytical grade and all the solutions were prepared with distilled water.

\section{Grafting of Jute fibres with AN}

Jute fibres was soaked in $\mathrm{NaOH}$ solution (20\%) for $24 \mathrm{~h}$., washed with hot water, neutralized with diluted acetic acid, then dried until they attain a constant wt $\left(\mathrm{W}_{\mathrm{o}}\right)$. Thereafter, swelled Jute fibres were immersed in the grafting solution which contains monomer and solvent. The direct radiation was used at different irradiation doses. The grafted fibres were washed and extracted to rid of the residual monomer and homo-polymer, and then dried and weighed $\left(\mathrm{W}_{\mathrm{g}}\right)$. The degree of grafting was calculated as shown in Eq.1.

$$
\text { Graft yield }(\%)=\left[\left(\mathrm{W}_{\mathrm{g}}-\mathrm{W}_{\mathrm{o}}\right) / \mathrm{W}_{\mathrm{o}}\right] \times 100
$$

Irradiation to the required doses was carried out in a ${ }^{60} \mathrm{Co}$ gamma-cell, India at the NCRRT, Egypt. The grafting process was carried out at a dose rate of $2.5 \mathrm{kGy} / \mathrm{h}$.

\section{Amidoximation}

The resulting grafted Jute fibres with polyacrylonitrile (PAN) was treated with a hydroxylamine-alcohol solution $(\mathrm{pH}=7)$ at $70^{\circ} \mathrm{C}$ for $4 \mathrm{~h}$, under reflux.
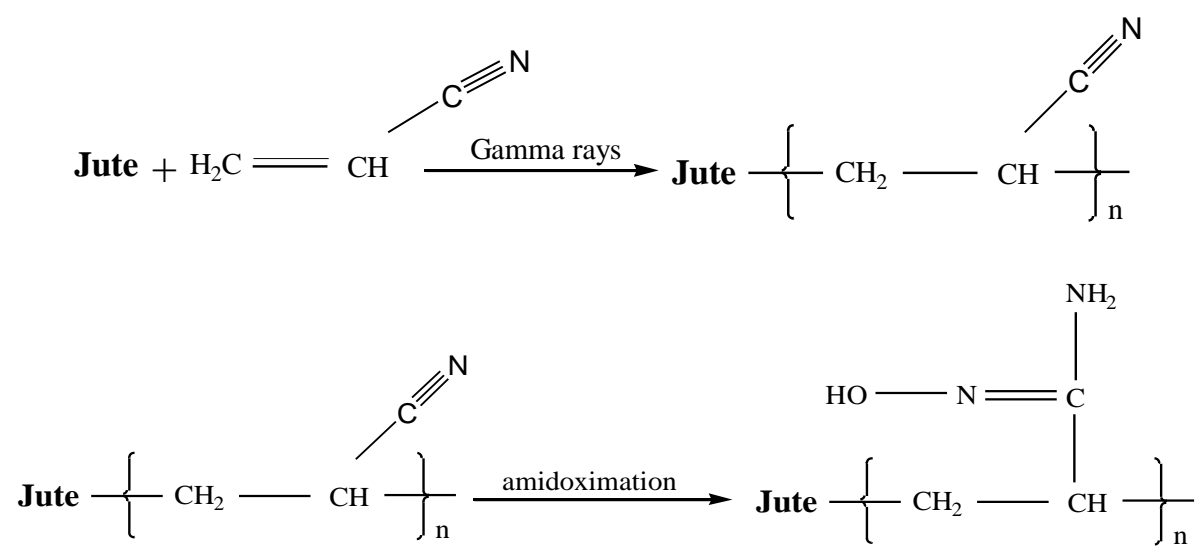

Scheme 1. The graft copolymerization of Jute fibres with AN followed by the amidoximation reaction of the nitrile group.

Egypt. J. Rad. Sci. Applic., Vol. 28, No. 1-2 (2015) 
The prepared amidoxime polymer was washed with distilled water to remove excess hydroxylamine, and then the samples were dried at $70^{\circ} \mathrm{C}$ for 6h(Nasef et al., 2004), as shown in Scheme 1..

\section{Characterization of grafted and amidoximated Jute fibres}

The untreated Jute, Jute-g-PAN and Jute-g-PAO were analysed by FT-IR spectroscopy, in a wide range wavelength $\left(400-4000 \mathrm{~cm}^{-1}\right)$, and in solid state using Mattson 5000 FTIR spectrometer (Mattson Instruments, Madison, WI). SEM study of the prepared Jute fibres was carried out by JSM-640, JEOL at $15 \mathrm{kV}$. The dried sample was sputter-coated with gold using a microscope sputter coater and viewed through the microscope. XRD studies were performed using Philips (PW 1390), using Nickel-filtered "Cu-K $\alpha$-radiation". The XRD patterns were scanned from $2^{\circ}$ to $40^{\circ}$ at room temperature. TGA was determined by using Shmadzu-30 (TGA-30) at a heating rate of $10^{\circ} \mathrm{C} / \mathrm{min}$ in air over a temperature range from room temperature up to $600^{\circ} \mathrm{C}$.

Determination of metal ions adsorption capacity by amidoximated Jute fibres

The adsorption capacity $(q)$ of Jute fibres towards the different metal ions was determined. A constant wt of dry treated Jute fibres $(0.2 \mathrm{~g})$ was immersed in a definite volume $(50 \mathrm{ml})$ of metal salts solutions from $\mathrm{CuSO}_{4}, \mathrm{NiSO}_{4}$, $\left(\mathrm{NH}_{4}\right)_{2} \mathrm{SO}_{4} \mathrm{FeSO}_{4} \cdot 6 \mathrm{H}_{2} \mathrm{O}$ and $\mathrm{Pb}\left(\mathrm{NO}_{3}\right)_{2}$, at a constant concentration of $(0.05 \mathrm{M})$ for all, in flasks under shaking. The remaining metal ions concentrations were determined by using standard solution of EDTA (Skoog et al., 1995). The adsorption capacity $q(\mathrm{mg} / \mathrm{g})$ was calculated according to Eq. 2 .

$$
q=\left(C_{o}-C_{e}\right) V / W
$$

where, $\mathrm{C}_{\mathrm{o}}$ and $\mathrm{C}_{\mathrm{e}}$ are the initial and equilibrium metal ion solution concentrations ( $\mathrm{mg} / \mathrm{l})$, respectively, $\mathrm{W}$ is the wt of treated Jute fibres $(\mathrm{g})$ and $\mathrm{V}$ is the volume of metal salt solution (L).

\section{Results and Discussion}

\section{Graft copolymerization of Jute fibres with AN}

The effect of different grafting conditions such as monomer concentration and irradiation dose on the grafting yield was studied as shown in Fig. 1. In this regard, preliminary experiments monitored that the most suitable solvent mixture Egypt. J. Rad. Sci. Applic., Vol. 28, No. 1-2 (2015) 
was $\mathrm{H}_{2} \mathrm{O} / \mathrm{MeOH}(1: 1)$, depending on the swelling parameters of both of cellulosic fibres and AN. The degree of grafting yield increased promptly by increasing AN per-cent up to $30 \%$, thereafter the graft yield per-cent did not increase significantly up to $50 \%$ and it tended to level off. This is because higher monomer concentration causes suppression of the monomer diffusion due to the increase in the viscosity of the grafting medium under the homo polymers formation (Bador, 1991). The effect of irradiation dose as an important factor in the grafting process was investigated. It was found that by increasing the irradiation dose, the grafting yield increased up to $30 \mathrm{kGy}$, in which, the increasing in the irradiation dose led to more free radical formation in the grafting sites, which led to the increasing of the grafting yield. By increasing the irradiation dose beyond $30 \mathrm{kGy}$, the graft yield slightly increased, due to formation of the homo polymers (Hegazy, 2012). At the optimum conditions, the highest graft yield obtained was $12 \%$ of AN onto the Jute fibres. The optimum conditions were recorded at $30 \% \mathrm{AN}, 40 \mathrm{kGy}$ and solvent mixture of (1:1) $\mathrm{MeOH} / \mathrm{H}_{2} \mathrm{O}$.
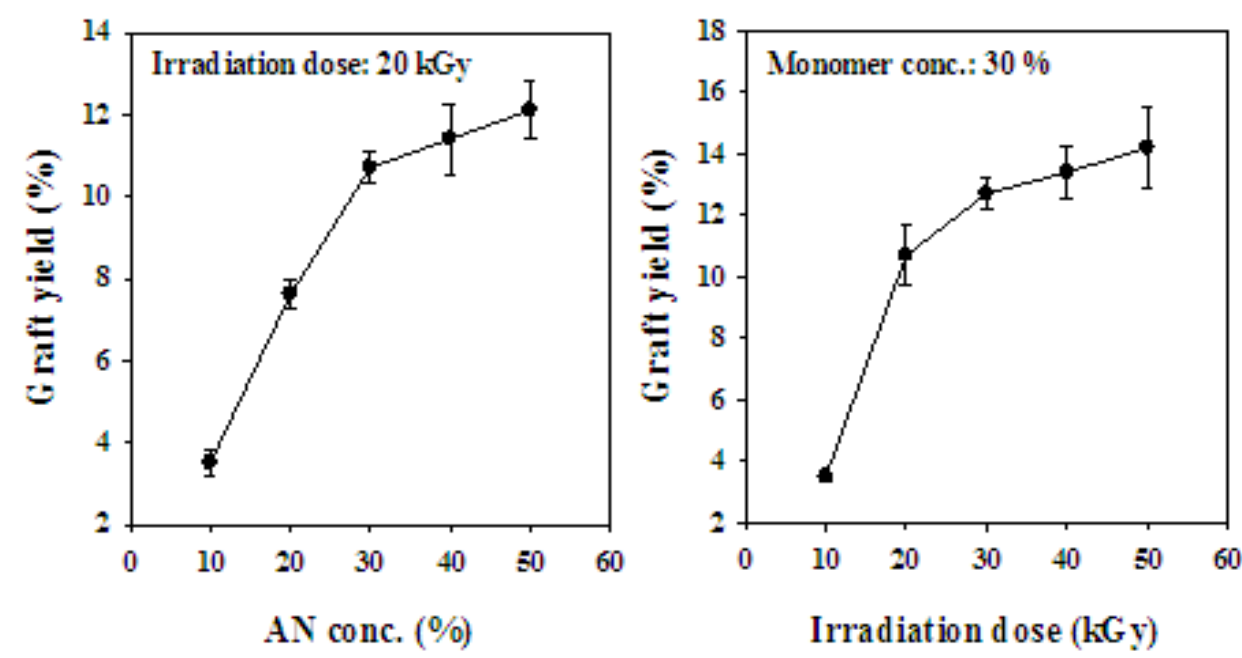

Fig. 1. Effect of irradiation dose and AN concentration on the graft yield of PAN onto Jute fibres.

\section{Characterization of grafted and amidoximated Jute fibers}

\section{Fourier transform infrared (FT-IR)}

Structural changes of untreated Jute fibre, Jute-g-PAN and Jute-g-PAO were characterized by FTIR spectroscopy as shown in Fig. 2. As shown in Fig. 2a, the 
IR spectrum of Jute fibres, as an example of cellulosic materials showed an absorption bands at $3448 \mathrm{~cm}^{-1}, 2923 \mathrm{~cm}^{-1}, 1650-1640 \mathrm{~cm}^{-1}$ due to the stretching vibration of $-\mathrm{OH}$, due to $\mathrm{C}-\mathrm{H}$ stretching vibration, corresponding to water associated with cellulose, respectively. In addition, it showed absorption bands at $1375-1320 \mathrm{~cm}^{-1}$ and at $1047-1004 \mathrm{~cm}^{-1}$ due to corresponding to $\mathrm{C}-\mathrm{H}$ bending of cellulose, and due to the stretching vibration of $\mathrm{C}-\mathrm{O}$, respectively. The absorption band seen at $2245 \mathrm{~cm}^{-1}$, due to the nitrile group-CN is indicative that the grafting of AN has been occurred as shown in Fig. 2b (Langenbach et al., 2003). The changes in the FTIR spectra after amidoximation process were shown in Fig. 2c. The characteristic band of $-\mathrm{CN}$ group at $2245 \mathrm{~cm}^{-1}$ was disappeared, and accompanied with the appearing of a broad band at 3000-3500 $\mathrm{cm}^{-1}$ for $(\mathrm{N}-\mathrm{H}$ and $\mathrm{O}-\mathrm{H}$ stretching vibration), at $1650 \mathrm{~cm}^{-1}$ for $(\mathrm{C}=\mathrm{N}$ stretch vibration) and a broad band at $920 \mathrm{~cm}^{-1}$ for (N-O stretch vibration) (Ekebafe et al., 2010).

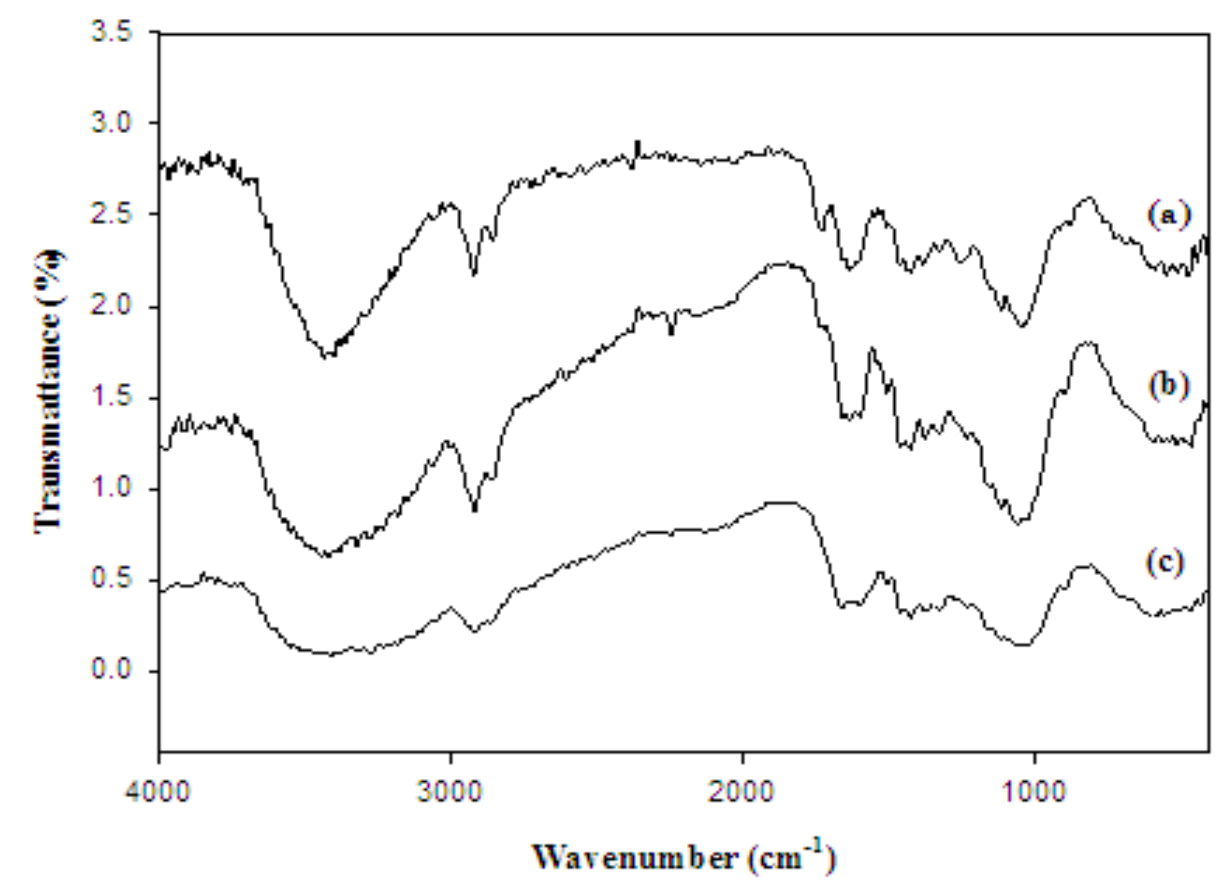

Fig. 2. FTIR spectra of: (a) pure Jute, (b) Jute-g-PAN and (c) Jute-g-PAO fibres.

\section{$X$-ray diffraction $(X R D)$}

The XRD spectra of untreated Jute fibre, Jute-g-PAN and Jute-g-PAO were studied as shown in Fig. 3. The Jute fibres showed a definite characterized Egypt. J. Rad. Sci. Applic., Vol. 28, No. 1-2 (2015) 
peak at $2 \theta=22.45^{\circ}$. A sharp peak can be noticed that indicates the high crystalline nature of Jute fibres, which is attributed to the great crystalline lignin (Leonard et al., 2002) in the Jute fibres composition.

The intensity of the characterized peak of Jute fibres was decreased after grafting with PAN, which have a lower crystal lattice than lignin component in the untreated Jute fibres. After the amidoximation process, a slight increase in the crystalinity was observed, due to the conversion of the nitrile groups to amidoxime groups with higher crystal lattice.

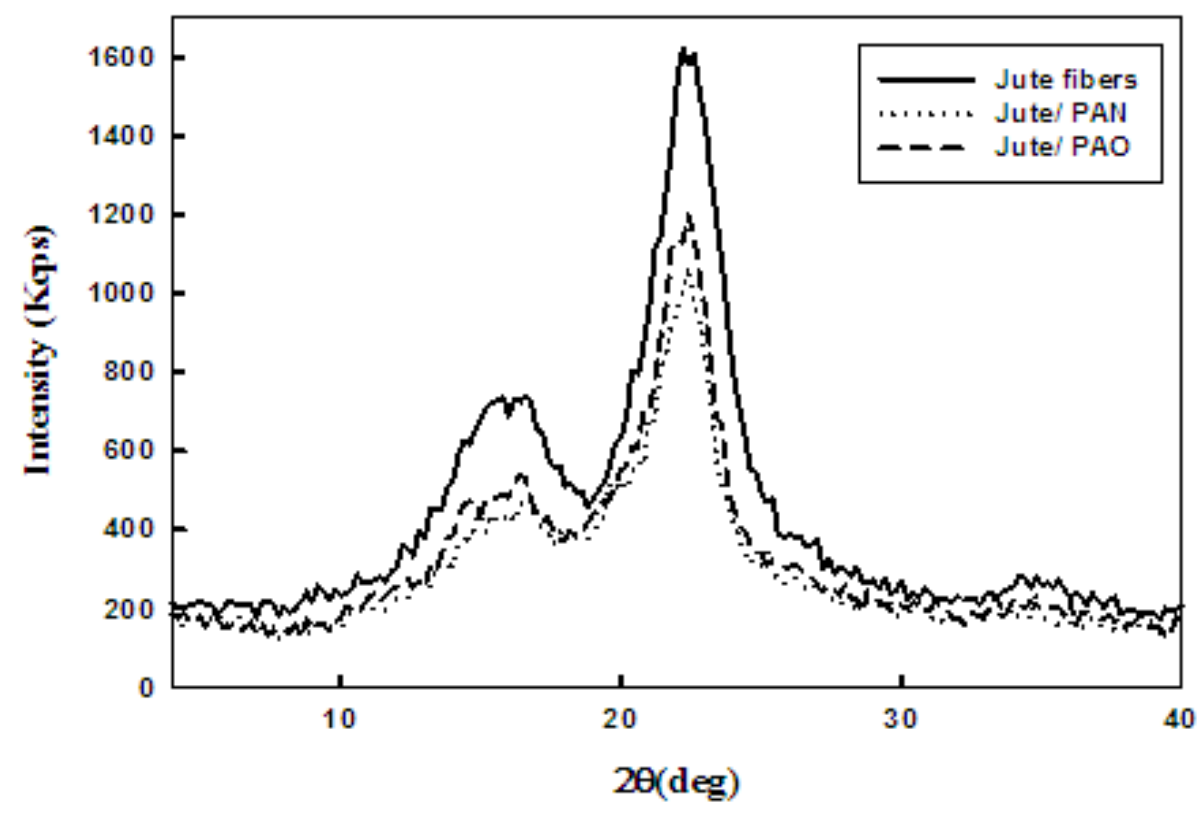

Fig. 3. XRD scans of untreated Jute, Jute-g-AN and Jute-g-PAO fibers.

\section{Scanning electron microscopy (SEM)}

The SEM was used to compare the differences in the surface morphology and the physical appearance of untreated Jute fibres, Jute-g-PAN and Jute-g-PAO as shown in Fig. 4. The SEM micrographs of untreated Jute fibres showed the smooth crystalline appearance as shown in Fig. 4a. After the grafting and amidoximation of AN groups, it can be seen that the graft copolymer form a thick spongy layer on the Jute surface that increase the diameter of the fibres in mostly uniform shape as shown in Fig. 4b.

Egypt. J. Rad. Sci. Applic., Vol. 28, No. 1-2 (2015) 


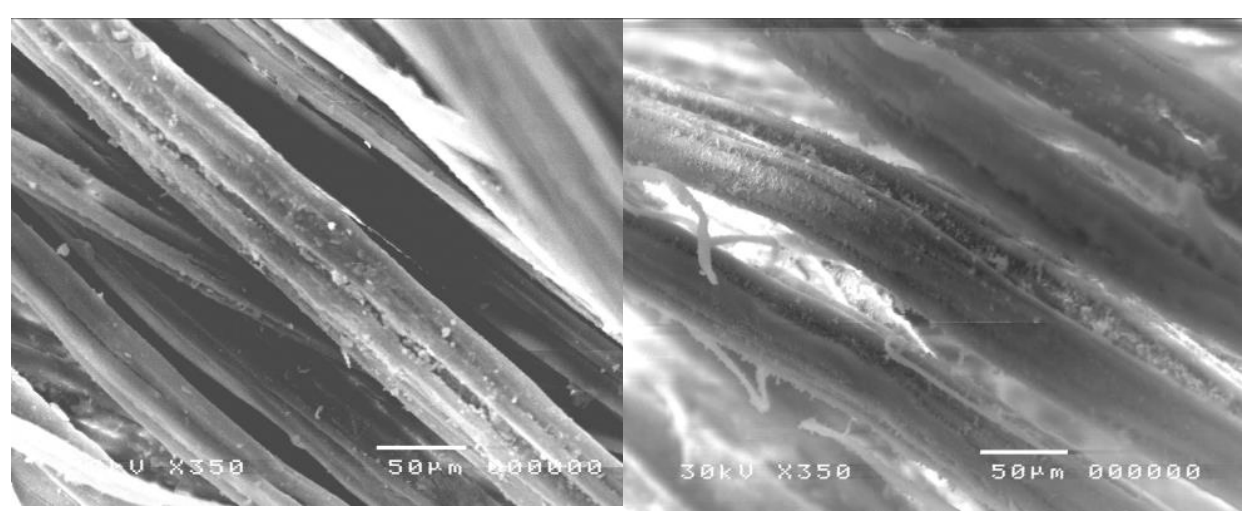

(a)

(b)

Fig. 4. SEM micrographs of the surface morphology of: (a) untreated Jute and (b) Jute-g-PAO fibres.

\section{Thermogravimetric analysis (TGA)}

The TGA thermograms and the corresponding rate of the thermal decomposition curves of untreated Jute fibres, Jute-g-PAN and Jute-g-PAO were studied as shown in Fig. 5.

The results showed that the thermal stability of grafted Jute fibres with PAN and amidoximaed fibers was higher than untreated Jute fibres. This enhancement in thermal stability could be attributed to the formation of polymer cross-linked upon the Jute fibres backbone (Badawy et al., 2000).

From Fig. 5. it can be noticed that there is an increase in the maximum temperature of the thermal decomposition reaction $\left(\mathrm{T}_{\max }\right)$ after grafting with PAN and after amidoximation process. The $\mathrm{T}_{\max }$ for Jute, Jute-g-PAN and Jute-g-PAO were found to be 362,372 and $380^{\circ} \mathrm{C}$, respectively. In addition, the wt remaining (\%) were 5, 13 and $28 \%$ for Jute, Jute-g-PAN and Jute-g-PAO, respectively at $500^{\circ} \mathrm{C}$. This could be attributed to the high stability of each component (amidoxime group, backbone graft chain and the cellulosic chain), which accordingly need more heat to be decomposed forming multiple stages of degradation and higher temperature range. Also, the rate of thermal decomposition was found to take the order of Jute-g-PAN, Jute fibres, then Juteg-PAO, respectively.

Egypt. J. Rad. Sci. Applic., Vol. 28, No. 1-2 (2015) 

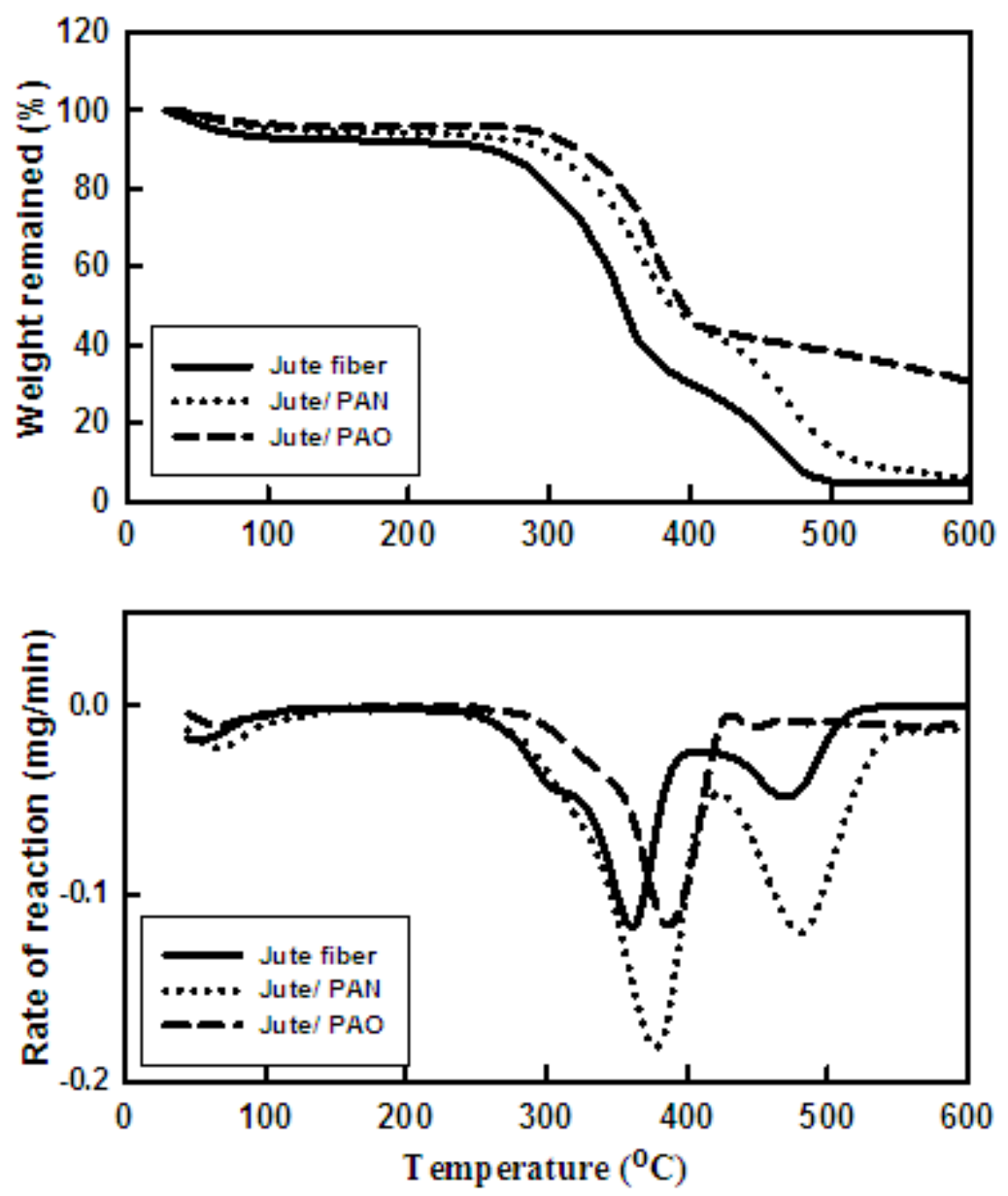

Fig. 5. TGA thermograms and the corresponding rate of thermal decomposition curves of: untreated Jute, Jute-g-PAN and Jute-g-PAO fibres.

\section{Adsorption of metal ions by amidoximated grafted Jute fibres}

The Jute-g-PAO was used as an adsorbent matrix for some heavy metal ions such as: $\mathrm{Fe}^{+2}, \mathrm{~Pb}^{2+}, \mathrm{Cu}^{2+}$ and $\mathrm{Ni}^{2+}$. Previous reports proved that the amidoxime groups form a complex by 6 coplanar donor atoms in the equatorial plane of the ion, so it acts as strong complexion agent for metal ions (Badawy et al., 2006). The influence of parameters which may affect, the adsorption capacity of Jute-g-PAO fibres towards the heavy metal ions such as, $\mathrm{pH}$ and contact time were investigated as shown in Fig. 6.

Egypt. J. Rad. Sci. Applic., Vol. 28, No. 1-2 (2015) 


\section{Effect of $\mathrm{pH}$ on the adsorption capacity}

The effect of $\mathrm{pH}$ on the adsorption capacity $(q)$ of Jute-g-PAO fibres towards the different metal ions at different $\mathrm{pH}$ values at constant temperature $\left(30^{\circ} \mathrm{C}\right)$ and for 60 min was studied as shown in Fig. 6. The investigated $\mathrm{pH}$ range was limited between 2-7 to avoid the formation of precipitation of metal ions at alkaline medium (Yiming et al., 2012). The metal ion solutions concentration was kept constant at $0.05 \mathrm{M}$. The adsorption capacity of Jute-g$\mathrm{AO}$ was found to increase promptly, for all applied metal ions, with increasing the $\mathrm{pH}$ up to 4 , and then it tended to increase slightly by further increase in $\mathrm{pH}$ up to 7. At low $\mathrm{pH}$ range, more $\mathrm{H}^{+}$competed with metal ions at adsorption sites, which made it more difficult for metal ions to bind with activated sites. Based on these conditions, the adsorption capacity towards different metal ions by Jute-g-PAO may be arranged as: $\mathrm{Fe}^{2+}>\mathrm{Pb}^{2+}>\mathrm{Cu}^{2+}>\mathrm{Ni}^{2+}$, which could be attributed to the complex stability, formed between the metal ions and the polymer functional groups. The higher stability of complex, the higher the affinity was obtained (Bador, 1991). Also, this selectivity order is in good accordance with the decreasing order of hydrated ionic radii of these metal ions in aqueous solution (Chen et al., 2010 and Lide, 1998).

\section{Effect of contact time on the adsorption capacity}

The effect of contact time on the adsorption capacity $(q)$ of Jute-g-PAO fibres towards the different metal ions, at constant $\mathrm{pH}(4)$ and temperature $\left(30^{\circ} \mathrm{C}\right)$ was studied, as shown in Fig. 6. It can be seen that the absorption capacity of treated Jute fibres towards the different metal ions increased significantly after 10 $\mathrm{min}$, and it tended to increase with lower rate with increasing the time up to 60 min. Above $60 \mathrm{~min}$, the adsorption capacity tended to level off. The rapid initial adsorption was due to the abundant available chelating oxime sites on the surface of treated Jute fibres and the high concentration of metal ions (Yiming et al., 2012), with increasing the contact time, the adsorption rate decreased and finally reached equilibrium, due to limited vacant adsorption sites available on the treated Jute fibres. It was found also that, at the same conditions, the adsorption capacity towards different metal ions took the order of: $\mathrm{Fe}^{2+}>\mathrm{Pb}^{2+}>\mathrm{Cu}^{2+}>\mathrm{Ni}^{2+}$, according to their complex stability and the hydrated ionic radii (Bador, 1991, Chen et al., 2010 and Lide, 1998).

Egypt. J. Rad. Sci. Applic., Vol. 28, No. 1-2 (2015) 


\section{Effect of initial concentration on the adsorption capacity}

The effect of initial concentration of metal ions on the adsorption capacity of Jute-g-PAO was determined for five different metal ion concentrations $(0.03$, $0.05,0.1,0.3$, and $0.5 \mathrm{M}$ ), and the results are given in Fig. 7. it can be seen that the adsorption of metal ions increased almost linearly with the increase in the initial metal ion concentration up to $0.1 \mathrm{M}$. This could be attributed to the acceleration of the metal ion diffusion into the polymeric network. The maximum adsorption capacity $\left(q_{m}\right)$ of Jute-g-PAO towards the metal ions can be determined by using the Langmuir model (Deng et al., 2003). The Langmuir adsorption isotherm assumes that the adsorption process occurred at specific homogeneous sites on the Jute-g-PAO and is the most commonly used for monolayer adsorption process, as shown in Eq. 3:

$$
\mathrm{q}_{\mathrm{e}}=\mathrm{q}_{\mathrm{m}} \mathrm{b} \mathrm{C}_{\mathrm{e}} /\left(1+\mathrm{b} \mathrm{C}_{\mathrm{e}}\right)
$$

where, $q_{e}$ is the equilibrium adsorption capacity of metal ion on Jute-g-PAO $(\mathrm{mg} / \mathrm{g}), C_{e}$ is the equilibrium metal ion concentration $(\mathrm{M}), q_{m}$ is the monolayer adsorption capacity and $b$ is the Langmuir adsorption constant $(\mathrm{L} / \mathrm{mg})$. The slopes and intercepts of plots of $C_{e} / q_{e}$ versus $\boldsymbol{C}_{e}$ were used to determine $q_{m}$ and $b$ as shown in Fig. 7. The data of $q_{m}, b$ and correlation coefficient $\left(r^{2}\right)$ were summarized in Table 1. It can be concluded that the maximum adsorption capacities of Jute-g-PAO were: 45.5, 39.9, 27.6 and $10.1(\mathrm{mg} / \mathrm{g})$ for $\mathrm{Fe}^{2+}, \mathrm{Pb}^{2+}$, $\mathrm{Cu}^{2+}$ and $\mathrm{Ni}^{2+}$, respectively.
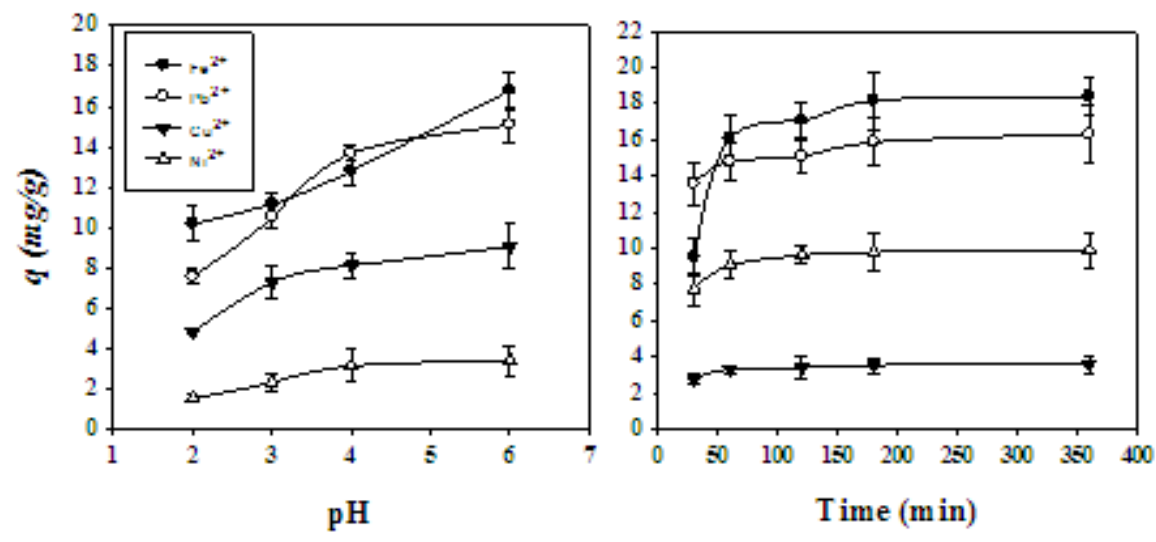

Fig.6. Effect of $\mathrm{pH}$ and contact time on the absorption of different metal ions by amidoximated Jute fibres.

Egypt. J. Rad. Sci. Applic., Vol. 28, No. 1-2 (2015) 

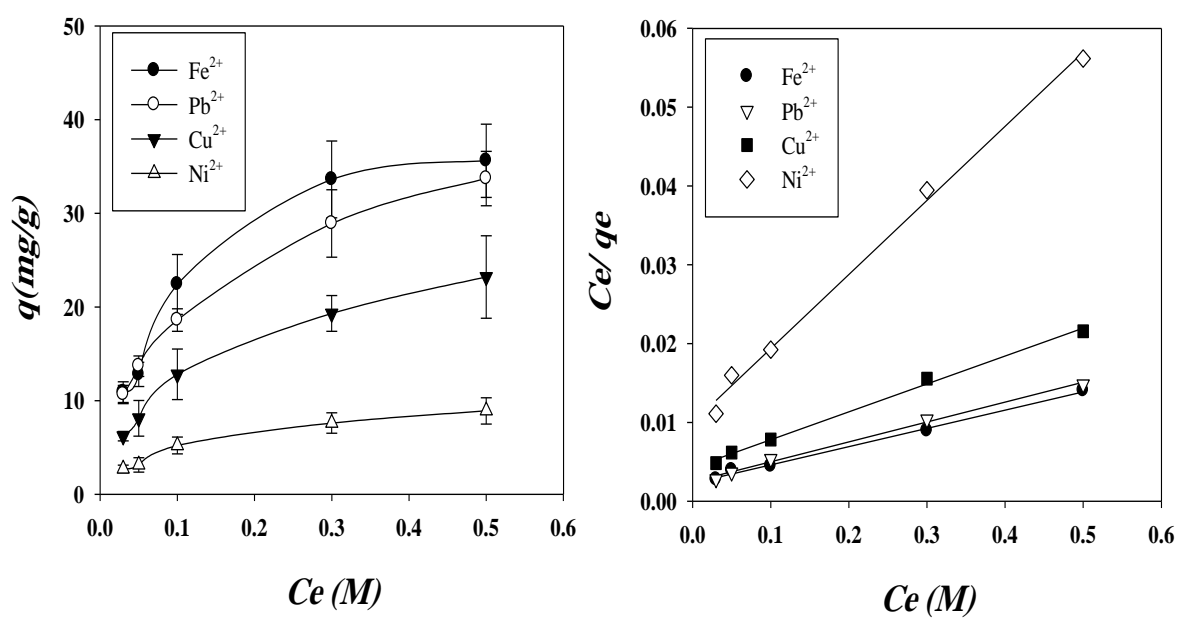

Fig. 7. Effect of initial metal ions concentrations on adsorption capacity and the adsorption isotherm of amidoximated Jute fibres.

TABLE 1. Langmuir adsorption parameters of amidoximated Jute fibres towards different metal ions.

\begin{tabular}{|c|c|c|c|c|}
\hline \multirow{2}{*}{$\begin{array}{c}\text { Langmuir adsorption } \\
\text { parameters }\end{array}$} & \multicolumn{4}{|c|}{ Adsorbed metal ions } \\
\cline { 2 - 5 } & $\mathbf{F e}^{\mathbf{2 +}}$ & $\mathbf{P b}^{\mathbf{2 +}}$ & $\mathbf{C u}^{\mathbf{2 +}}$ & $\mathbf{N i}^{\mathbf{2 +}}$ \\
\hline $\boldsymbol{q}_{\boldsymbol{m}}(\mathrm{mg} / \mathrm{g})$ & 45.5 & 39.9 & 27.6 & 10.1 \\
\hline $\boldsymbol{b}$ & 0.0023 & 0.0025 & 0.0044 & 0.01 \\
\hline $\boldsymbol{r}^{2}$ & 0.9953 & 0.9953 & 0.9953 & 0.9953 \\
\hline
\end{tabular}

\section{Conclusions}

This work dealt with the grafting of Jute fibres with PAN, followed by conversion of the nitrile groups into amidoxime groups. The prepared Jute-gPAO was used as an adsorbent for different metal ions from their solutions. The adsorption capacity of Jute-g-PAO was enhanced at moderate $\mathrm{pH}$ range up to 4 and increased with increasing of the contact time at constant temperature. The adsorption capacities of Jute-g-PAO towards the adsorbed metal ions follow the order of: $\mathrm{Fe}^{2+}>\mathrm{Pb}^{2+}>\mathrm{Cu}^{2+}>\mathrm{Ni}^{2+}$.

\section{References}

Akkaya, R. and Ulusoy, U. (2008) Adsorptive features of chitosan entrapped in polyacrylamide hydrogel for $\mathrm{pb}^{2+}, \mathrm{UO}_{2}^{2+}$, and $\mathrm{Th}^{4+"}$. J. Hazard. Mater., 151, 380 .

Egypt. J. Rad. Sci. Applic., Vol. 28, No. 1-2 (2015) 
Badawy, S. M., Dessouki, A. M. and Abu-Eittah, R. H. (2000) Synthesis and characterization of chelating filter paper with amidoxime groups for selective adsorption of uranium, World filtration congress 8, Brighton, UK, pp. 3-7.

Badawy, S. M., Sokker, H. H. and Dessouki, A. M. (2006) Chelating polymer granules prepared by radiation-induced homopolymerization. II. Characterizations. J. Appl. Polym. Sci., 99, 1180.

Bador, G. (1991) Structure investigation of polymer; Elis Horwood Limited; London, p. 127.

Bayramoglu, G., Arica, M. Y. and Bektas, S. (2007) Removal of $\mathrm{Cd}(\mathrm{II}), \mathrm{Hg}(\mathrm{II})$, and $\mathrm{Pb}$ (II) ions from aqueous solution using p(HEMA/chitosan) membranes. $J$. Appl. Polym. Sci., 106, 169.

Bhattacharya, A. and Misra, B. N. (2004) Grafting: A Versatile Means to Modify Polymers: Techniques, Factors and Applications. Prog. Polym. Sci., 29, 767.

Chen, S. B., Ma, Y. B., Chen, L. and Xian, K. (2010) Adsorption of aqueous Cd2+, $\mathrm{Pb} 2+, \mathrm{Cu} 2+$ ions by nano-hydroxyapatite: Single- and multi-metal competitive adsorption study. Geochem. J., 44, 233.

Deng, S. B., Bai, R. B. and Chen, S. (2003) Aminated polyacrylonitrile fibers for lead and copper removal. Langmuir., 19, 5058.

Ekebafe, L. O., Imanah, J. E. Ekebafe, M. O. and Ugbesia, S. O. (2010) Graft Polymerization of polyacrylonitrile onto rubber (hevea brasiliensis) seed shell-cellulosic and its utilization potential for heavy metal uptake from aqueous medium. Pac. J. Sci. Technol., 11, 488.

Hegazy, D. E. (2012) Selectivity of acrylic acid radiation grafted non-woven polypropylene sheets towards $\mathrm{Cu}, \mathrm{Ni}$ and $\mathrm{Co}$ heavy metals ions. J. Chem. Engin., 1, 42.

Jang, S. H., Jeonga, Y. G. Min, B. G., Lyoo, W. S. and Lee, S. C. (2008) Preparation and lead ion removal property of hydroxyapatite/polyacrylamide composite hydrogels. J. Hazard. Mater., 159, 294.

Langenbach, M. R., Schmidt, J. and Zirngibl, H. (2003) Comparison of biomaterials in the early postoperative period, Surg. Endosc., 17, 1105.

Laus, R. and De Favere, V. T. (2011) Competitive adsorption of $\mathrm{Cu}$ (II) and $\mathrm{Cd}(\mathrm{II})$ ions by chitosan crosslinked with epichlorohydrine-triphosphate. BiosourceTechnol., 102, 8769.

Leonard, Y. and Mwaikambo, M. P. (2002) chemical modification of hemp, sisal, jute, and kapok fibers by alkalization, J. Appl. Polym. Sci., 84, 2222.

Lide, D. R. (1998) Handbook of Chemistry and Physics. $79^{\text {th }}$ ed., CRC Press, Boca Raton.

Liu, C., Bai, R. and Ly, Q. S. (2008) Selective removal of copper and lead ions by diethylenetriamine- functionalized adsorbant: Behaviors and mechanisms. Water Res., 42, 1511.

Egypt. J. Rad. Sci. Applic., Vol. 28, No. 1-2 (2015) 
Nasef, M. M. and Hegazy, E. A. (2004) Preparation and applications of ion exchange membranes by radiation-induced graft copolymerization of polar monomers onto non-polar films. Prog. Polym. Sci., 29, 499.

Othman, S. H., Sohsah, M. A., Ghoneim, M. M., Sokkar, H. H., Badawy, S. M. and El-Anadouli, B. E. (2005) Adsorption of hazardous ions from radioactive waste on chelating cloth filter. Radiat. Phys. Chem., 75, 278.

Skoog, D. A., West, D. M., Holler, F. J. and Crouch, S. R. (1995) Analytical Chemistry: An Introduction, $7^{\text {th }}$ ed., Chapter 15, p. 345.

Yiming, Z., Liangliang, Z., Shiyu, F., Liming, Z. and Huaiyu, Z. (2012) Adsorption behavior of $\mathrm{Cd}^{2+}, \mathrm{pb}^{2+}$, and $\mathrm{Ni}^{2+}$ from aqueous solutions on cellulose-based hydrogels. Bioresources, 7, 2752.

(Received: 23/02/2015;

accepted: 14/04/2015)

Egypt. J. Rad. Sci. Applic., Vol. 28, No. 1-2 (2015) 
